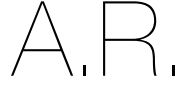

1 Escola Superior de Tecnologia da Saúde do Instituto Politécnico de Coimbra,

Rua 5 de Outubro, São Martinho do Bispo, 3046-854 Coimbra Portugal

*Endereço para correspondência:

Mariana Cordeiro

Rua Cidade Santarém, n. ${ }^{\circ} 27$, Casais da Charneca, 2025-143 Alcanede, Santarém, Portugal marianac1999@hotmail.com

Histórico do artigo:

Recebido a 26 de maio de 2020 Aceite a 16 de março de 2021

\title{
ÁCIDO ARISTOLÓQUICO - NEFROPATIA E O CANCRO
}

\author{
ARISTOLOCHIC ACID - NEPHROPATHY AND CANCER
}

Bruna Faria'; Cátia Bispo'; Mariana Cordeiro" ${ }^{1 *}$ Ana Baltazar ${ }^{1}$

RESUMO

O ácido aristolóquico é um composto natural tóxico, proveniente da família de uma herbácea perene, Aristolochia. Este pertence à família de ácidos nitrofenantrol carboxílicos e é uma mistura de dois ácidos estruturalmente semelhantes: ácido aristolóquico I e ácido aristolóquico II. As espécies de plantas que contém ácido aristolóquico são utilizadas essencialmente na medicina tradicional chinesa.

Este artigo pretende rever a relação entre o efeito tóxico do ácido aristolóquico e a ocorrência de nefropatia e cancro.

A ingestão de ácido aristolóquico provoca nefrotoxicidade, genotoxicidade e carcinogenicidade. A nefropatia por ácido aristolóquico e a nefropatia endémica nos Balcãs são causadas pela intoxicação alimentar por ácido aristolóquico e estão associadas à ocorrência de carcinoma urotelial do trato urinário superior. O ácido aristolóquico foi classificado como carcinogénico do grupo I pela International Agency for Research on Cancer.

O conhecimento da relação direta entre os efeitos tóxicos do consumo de ácido aristolóquico e de nefropatia por ácido aristolóquico e carcinoma urotelial do trato urinário superior deve ser considerada importante para a sua futura prevenção.

\section{PALAVRAS-CHAVE}

Ácido Aristolóquico, Ácido Aristolóquico e Cancro, Nefropatia por Ácido Aristolóquico

\section{ABSTRACT}

Aristolochic acid is a natural toxic compound, from the family of a perennial herb, Aristolochia. It belongs to the family of nitrophenanthrole carboxylic acids and is a mixture of two structurally similar acids: aristolochic acid I and aristolochic acid II. Plant species containing aristolochic acid were used primarily in traditional Chinese medicine.

The aim of this article is to review the relationship between the toxic effect of aristolochic acid and the occurrence of nephropathy and cancer.

Ingestion of aristolochic acid causes nephrotoxicity, genotoxicity and carcinogenicity. Aristolochic acid nephropathy and endemic nephropathy in the Balkans are derived from aristolochic acid food poisoning and are highly associated with the occurrence of urothelial carcinoma of the upper urinary tract. Aristolochic acid was classified as a group I carcinogen by the International Agency for Research on Cancer.

The knowledge of the direct relationship between the toxic effects of aristolochic acid consumption and the occurrence of aristolochic acid nephropathy and urothelial carcinoma of the upper urinary tract should be considered important for its future prevention.

KEYWORDS

Aristolochic acid, Aristolochic Acid and Cancer, Aristolochic Acid Nephropathy

\section{INTRODUÇÃO}

O ácido aristolóquico (AA) é um composto natural tóxico (1-3), proveniente da família de uma herbácea perene, Aristolochiaceae, que inclui mais de 500 espécies (4) como Aristolochia manshuriensis, Aristolochia fangchi, Radix Aristolochiae, Aristolochiae fructus, Aristolochiae herba, Asari radix et rizoma. No entanto, o AA encontra-se mais abundantemente nas espécies Aristolochia e Asarum (5-8). Este pertence à família de ácidos nitrofenantrol carboxílicos $(7,9,10)$ e é uma mistura de dois ácidos estruturalmente semelhantes: ácido 8-metoxi-6-nitro- fenanidro- (3,4-d) -1,3-dioxolo-5-carboxilico (AAl) e o ácido 6-nitro-fenanidro- (3,4-d) -1,3-dioxolo-5-carboxílico (AAll) (11-15).

As espécies que contém AA são utilizadas há mais de 2000 mil anos, essencialmente na medicina tradicional chinesa $(4,14)$. Todas as partes da planta são utilizadas na preparação de ervas medicinais, incluindo raízes, caules e as folhas (9), tendo estas fins terapêuticos antimicrobianos, anti-inflamatórios, antineoplásicos, comummente utilizados no tratamento de picadas de cobras, doenças como eczema, arterite, gota $(2,5,11,14,16)$, problemas 
ginecológicos e obstetrícia $(12,14,16,17)$. De fato, o seu primeiro uso na obstetrícia para estimular a expulsão da placenta, durante o parto, foi responsável pelo nome "Aristos lokos" ou "excelente entrega" (4). Contudo, o efeito deste composto pode variar de relativamente benigno a significativamente tóxico consoante a dosagem (11). O seu efeito tóxico começou a ser estudado quando nos meados dos anos 90, um grupo de aproximadamente 100 mulheres belgas saudáveis desenvolveu rapidamente insuficiência renal após a toma de um suplemento alimentar para perda de peso, contendo AA $(10,18)$. Foi ainda verificado que uma única dose alta ou a administração contínua de uma dose baixa de AA pode levar a uma reação tóxica (5), uma vez que a sensibilidade de cada indivíduo ao tóxico depende de fatores como a via de administração, características da planta ou parte utilizada (22), quantidade ingerida (23), bem como género, idade, fatores genéticos e atividade das enzimas responsáveis pela catalisação da biotransformação desta substância e os aspetos que as influenciam do mesmo $(5,9)$.

A nefropatia por ácido aristolóquico (AAN) é um termo usado que inclui qualquer forma de nefropatia intersticial tóxica causada por AA (4, $9,11,15)$. Semelhante a esta patologia ocorre também a nefropatia endémica nos Balcãs (BEN) $(4,11)$, sendo esta derivada de intoxicação alimentar crónica por AA, não apenas através de ervas ou dietas, mas também através de alimentos e água potável contaminados com este composto (10). Ambas as patologias têm alta associação à ocorrência de carcinoma urotelial do trato urinário superior (UTUC) $(2-4,9,11,19$, 20). Em 2002, o AA foi classificado como carcinogénico do grupo I pela International Agency for Research on Cancer (IARC) (2, 7, 9, 10, 14).

Em 2008 a prevalência de AAN registada a nível mundial contava com 128 casos na Bélgica, 4 na França, 4 no Reino Unido, 1 na Espanha, 1 na Alemanha, 2 nos Estados Unidos da América, 1 na Coreia, 6 no Japão, 116 na China e 33 em Taiwan (21). Posteriormente, em 2017 foi publicada uma revisão da literatura na qual foram reunidos todos os casos conhecidos de intoxicação por AA desde 1993 a 2013 (9). Todos os dados de prevalência encontrados apresentam-se compilados na Figura 1, não existindo registo de casos ocorridos em Portugal.
Neste sentido, pretende-se com este artigo rever as formas de exposição do AA, a sua metabolização e efeitos genotoxicos e carcinogénicos com breve referência aos conhecimentos sobre dose-resposta.

\section{Formas de Exposição ao Ácido Aristolóquico}

O ácido aristolóquico proveniente de plantas da família Aristolochia, além de presente em preparações terapêuticas da medicina chinesa e suplementos alimentares adquiridos via internet, poderá também ser encontrado na água subterrânea e ainda em vários alimentos por via de contaminação, tais como grãos de milho e trigo $(2,4,7,9,10,18)$. Neste último caso, a contaminação pode ocorrer através do solo, uma vez que os AAs são termicamente estáveis, não fotossensíveis e resistentes à degradação total pelas bactérias do solo, logo persistem no solo e são absorvidos pelas plantas circundantes através da absorção pelas raízes, acumulando-se e contaminando os seus grãos $(4,7,10)$ ou pela mistura de sementes de Aristolochia com estes grãos $(9,11)$. Ambas as formas levam à contaminação do pão, uma vez que o mesmo é preparado a partir de farinha derivada dos grãos contaminados, entrando assim na cadeia alimentar humana $(9,18)$. O AA foi descrito como altamente persistente no metabolismo das células vegetais e está presente em produtos alimentícios por um longo período (9).

\section{Processo de Metabolização do Ácido Aristolóquico}

Todas as exposições humanas conhecidas ao AA resultaram da ingestão oral (9). Após ingerido é absorvido no trato gastrointestinal e distribuído por todo o corpo $(1,9)$. O ácido aristolóquico é transformado em $\mathrm{N}$-hidroxiaristolactam (AL-NOHs) por meio da reação de nitrorredução, isto é redução parcial do grupo nitro (-NO2 que nas estruturas de AA desempenha um papel importante na mutagenicidade observada no DNA) (10) acompanhada do fecho do anel (1, 2, 4, 20). Posteriormente é convertido em intermediários reativos, aristolactamnitrenium, que são iões cíclicos eletrofílicos com cargas positivas deslocalizadas. Esta reação ocorre através da atividade das enzimas citosólicas e microssomais como citocromo P450 (CYP) 1A1, CYP1A2,

\section{Figura 1}

Prevalência de AAN a nível mundial

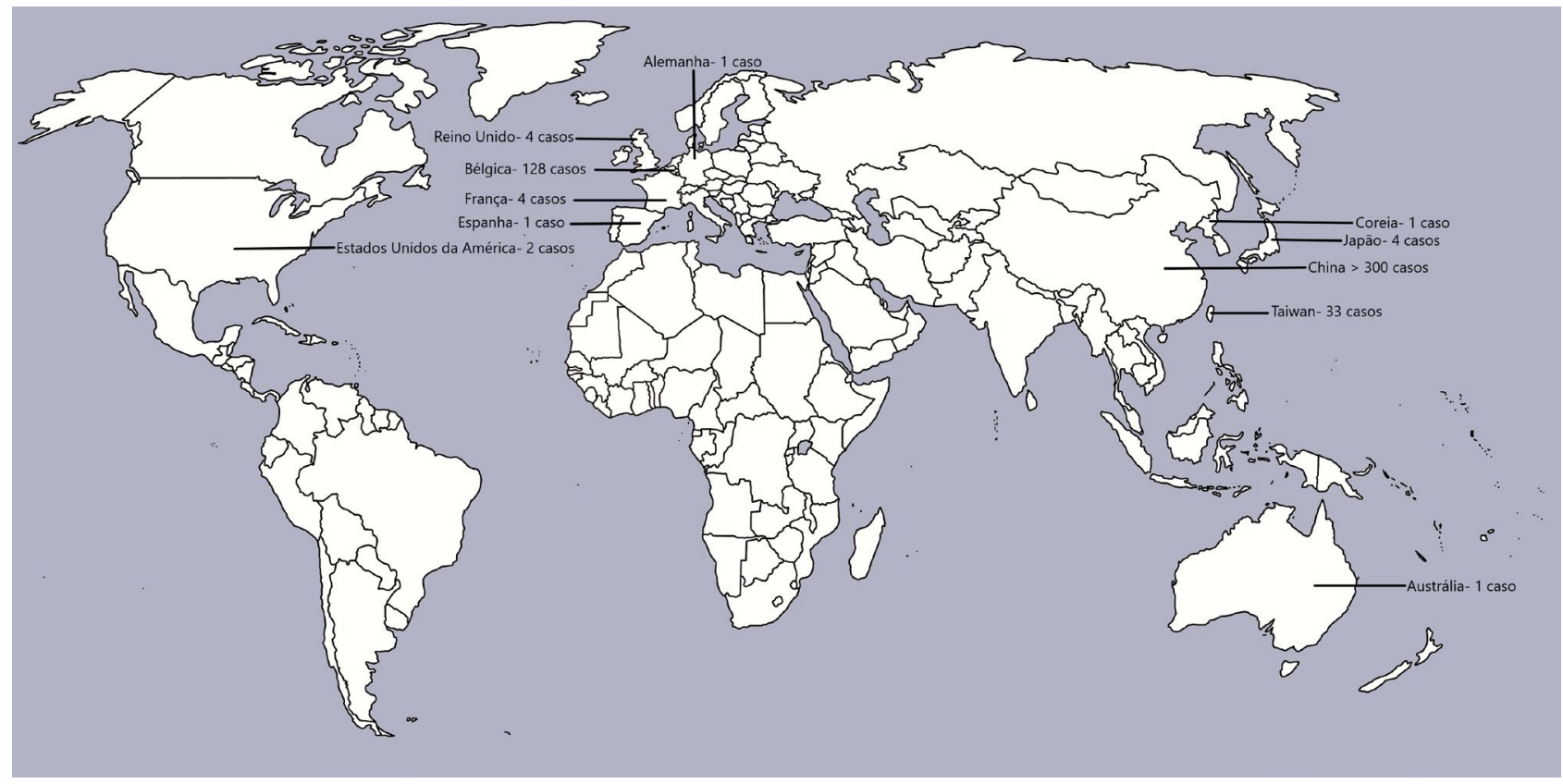

Fonte: compilação de dados da literatura de "An Integrated View of Aristolochic Acid Nephropathy: Update of the Literature" (9), "Aristolochic acid nephropathy: A worldwide problema" (21) e "Herbal remedies containing aristolochic acid and mushroom nephrotoxicity" (31) 
NAD (P) H, quinona oxidoredutase (NQO1) e xantina oxidase $(1,4,20)$. Durante este processo e em conduções aeróbicas, o constituinte AAI é desmetilado em AAla e depois reduzido a aristolactam la (Figura 2), enquanto que o constituinte AAll é reduzido apenas em condições anaeróbicas a aristolactam II (11).

Por fim, as formas de redução de AAl e AAll ligam-se preferencialmente aos grupos amina exocíclicos de bases purinas no DNA para formar adutos de AA-DNA, que são responsáveis por transversões de $A \rightarrow T$ que podem bloquear a transcrição e replicação do DNA no gene supressor de tumor p53 (11). Este processo leva à paragem do ciclo celular e à apoptose (20), provocando doença renal e cancro (1, 2, 18). Após a etapa de metabolização dos metabolitos AA (aristolactam I e aristolactam II), descobriu-se que os adutos de RNA e AA são excretados na urina e nas fezes, contudo existe também acumulação nos tecidos alvo (9) (Figura 3).
Sabe-se ainda que nem todos os pacientes com adutos de DNA derivado do ácido aristolóquico apresentam mutações no gene P53. Isso indica que a mutagenicidade induzida por Aristolochia não se deve apenas à formação de adutos de DNA. Portanto, outros mecanismos podem estar envolvidos ou outros agentes genotoxicos podem estar presentes na planta (20).

Alguns desses mecanismos genotoxicos poderão ser o aumento significativo dos níveis de óxido nítrico (NO), o aumento na concentração intracelular de $\mathrm{Ca}^{2+}$ (24) das células tubulares renais que leva à formação de espécies reativas de oxigênio ou a indução da autofagia dependente do gene 5, que promove a apoptose das células tubulares renais, embora seja uma hipótese controversa, uma vez que estudos sugerem que a autofagia induzida pelo ácido aristolóquico I pode atenuar a apoptose (20).

\section{Figura 2}

Via proposta para ativação metabólica e desintoxicação do ácido aristolóquico I (AAI), levando a lesão renal e urotelial

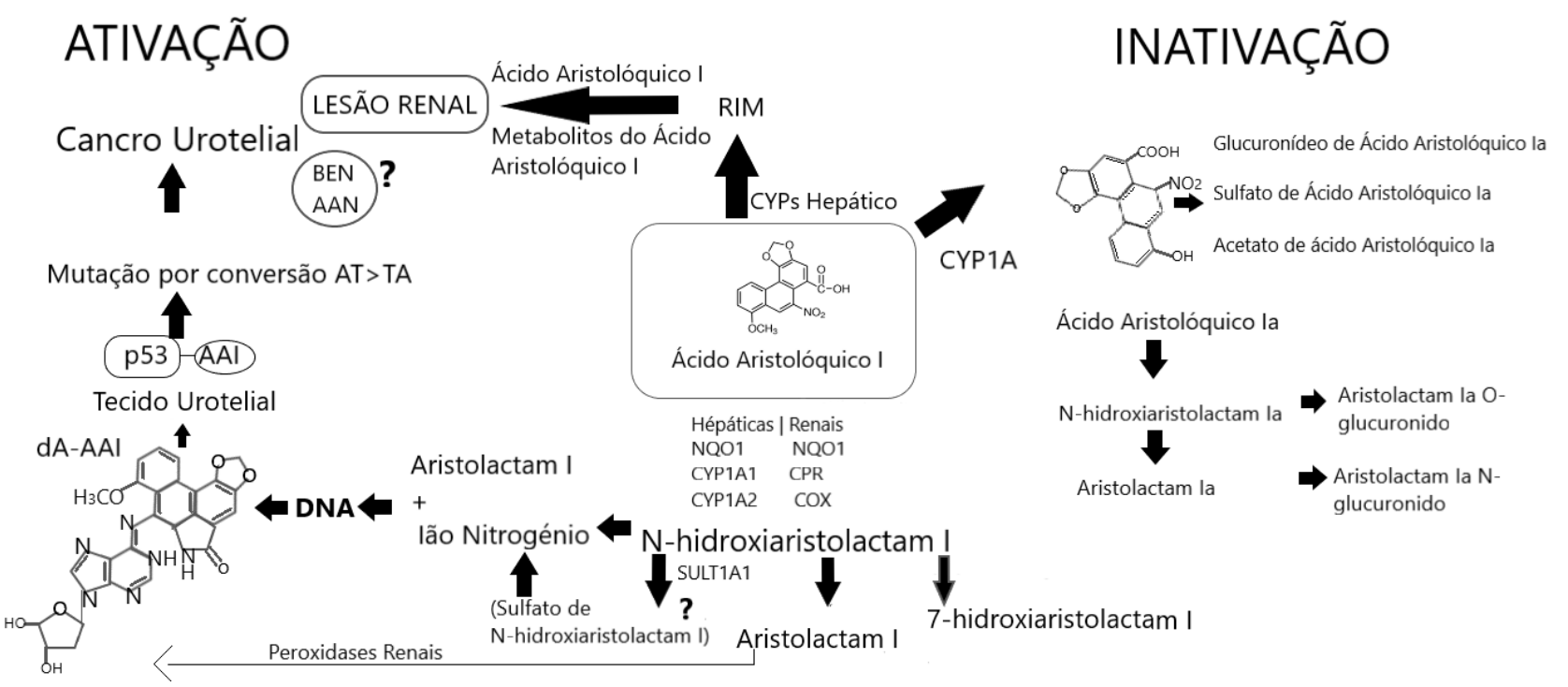

Fonte: adaptado de "Biotransformation enzymes in development of renal injury and urothelial cancer caused by aristolochic acid." Kidney Int. 2008 (16)

\section{Figura 3}

Via proposta para ativação metabólica e desintoxicação do ácido aristolóquico I (AAI), levando a lesão renal e urotelial

$$
\begin{aligned}
& \text { Ácido Aristolóquico } \\
& \text { I }(\mathrm{R}=\mathrm{OCH}) \text { e II }(\mathrm{R}=\mathrm{H})
\end{aligned}
$$

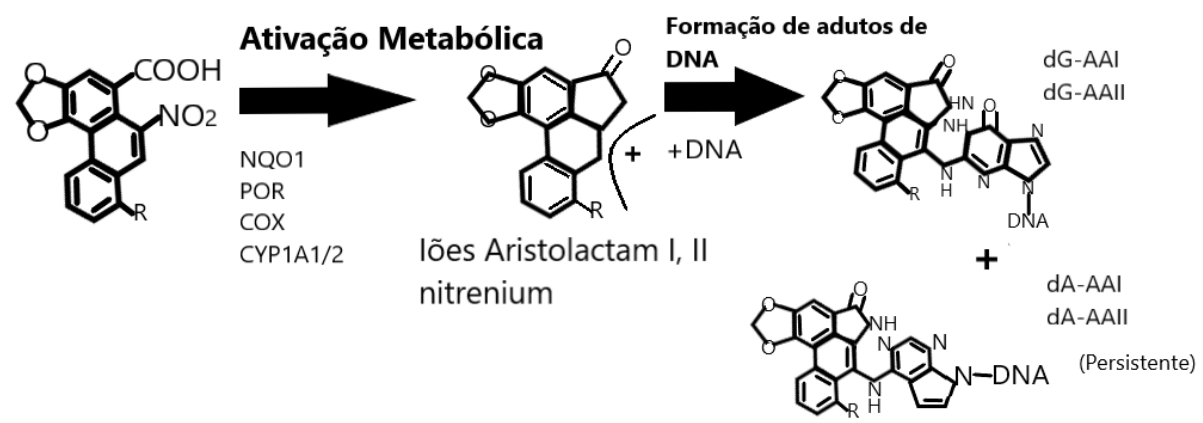

Cancro Urotelial

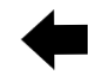

Transversões A:T > T:A no gene 553 e outros relacionados com o cancro 


\section{Efeitos Adversos e Manifestações Clínicas Provenientes da Ingestão de Ácido Aristolóquico}

O termo "nefropatia por ácido aristolóquico" (AAN) é usado para incluir qualquer forma de nefropatia intersticial (13), podendo ser acompanhada por carcinoma urotelial do trato superior (UTUC) em quase metade dos casos $(2,6,11,15)$, causada pela ingestão de plantas contendo ácidos aristolóquicos (AA) $(9,10,15)$. Esta insuficiência é caracterizada por fibrose intersticial extensa com atrofia, perda de túbulos e hiperplasia do urotélio, localizada principalmente no córtex superficial $(2,5)$ (Tabela 1).

Os sintomas apresentam um quadro clínico de hipertensão leve, anemia grave, aumento da creatinina sérica, diminuição da taxa estimada de filtração glomerular, proteinúria, glicosúria e/ou leucocitúria. A microalbuminúria e proteinúria do tipo tubular podem servir como indicadores de rastreamento precoce $(2,9,11,24)$.

Para diagnóstico, os indivíduos têm de apresentar insuficiência renal, bem como pelo menos dois dos seguintes critérios: (i) uma histologia renal exibindo fibrose intersticial com gradiente corticomedular; (ii) uma história de consumo de produtos à base de plantas que demonstrou a presença de AA; e (iii) a presença de adutos de AA-DNA (ou a transversão específica $A: T \rightarrow T: A$ no gene p53) numa amostra de tecido renal ou de um tumor urotelial $(4,9)$.

Apesar de irreversível $(2,4)$, é frequentemente feita terapia com glicocorticóides de forma a retardar a progressão (11). Contudo, quando existe evolução para doença renal crónica é necessário recorrer à hemodiálise (12\% dos casos) ou transplante renal $(88 \%$ dos casos) $(1,11,15)$.

A forma ambiental da AAN é a Doença Endémica dos Balcãs (BEN), observado em pacientes que vivem em países dos territórios dos Balcãs ao longo do rio Danúbio $(4,9,11)$, incluindo Sérvia, Roménia,
Croácia, Bulgária, Bósnia e Herzegovina (7). A intoxicação alimentar crónica por AA ocorre devido à contaminação dos solos agrícolas e água nos quais AA livres são libertados durante a decomposição da Aristolochia ou pela mistura das suas sementes com grãos destinados ao consumo $(2,7,9-11,18)$.

É descrita como uma doença renal aglomerada de caráter familiar, não hereditária (2) e lentamente progressiva (9), associada ao carcinoma urotelial do trato urinário superior (UTUC) $(2,4,10)$. Caracteriza-se morfologicamente como fibrose intersticial hipocelular extensa, associada a atrofia tubular envolvendo raios medulares que diminuem de intensidade da medula externa e do labirinto cortical para o córtex interno (4). Os sinais clínicos e sintomas de BEN são inespecíficos e frequentemente permanecem latentes por anos, até que se inicie declínio da função renal, ocorrendo fraqueza, dor lombar leve e palidez da pele e posteriormente anemia associada a uma perda significativa da função renal e proteinúria tubular (9).

Os quadros clínicos da BEN podem variar entre apenas nefropatia tubointersticial crónica levando à doença crónica tubular; ou apresentam simultaneamente UTUC (unilateral ou bilateral) com insuficiência renal e histopatologia típica de BEN; ou deterioração inicial da função renal seguida de UTUC (unilateral ou bilateral) (4).

Embora BEN e AAN compartilhem características semelhantes, diferem na progressão clínica, visto que no BEN o AA é ingerido em pequenas doses através de contaminação alimentar e na AAN o AA é ingerido em doses mais altas intencionalmente (9). Desta forma, é explicado o tempo de exposição ao AA distinto entre ambas as doenças para a manifestação de declínio da função renal ou tubular, sendo de 20 a 30 anos para a BEN em comparação com 2 anos para a AAN $(13,20)$.

Tabela 1

Quadro Síntese: Estudos que Retratam a Evidência Entre o Efeito Tóxico do Ácido Aristolóquico e a Ocorrência de Nefropatia/ Cancro

\begin{tabular}{|c|c|c|c|}
\hline ANO DE PUBLICAÇÃO & AUTORES & TIPOLOGIA & OBSERVAÇÕES \\
\hline 2014 & Luciano, R. L. et al (11) & Artigo de Revisão & $\begin{array}{l}\text { AA foi associado à ocorrência de AAN, sendo esta associada a } \\
\text { uma prevalência de } 40 \text { a } 45 \% \text { de carcinomas uroteliais. }\end{array}$ \\
\hline 2015 & Ma, L. et al (6) & Artigo Original & $\begin{array}{l}\text { A AAN é causada pela ingestão de AA e está associada a alta } \\
\text { prevalência }(40 \%-50 \%) \text { dos carcinomas uroteliais. }\end{array}$ \\
\hline 2016 & Abdullah, R. et al (14) & Artigo de Revisão & $\begin{array}{l}\text { Foi comprovado que o AA causa nefrotoxicidade, } \\
\text { genotoxicidade e carcinogenicidade, tendo sido classificado } \\
\text { como cancerígeno humano classe I pela IARC. }\end{array}$ \\
\hline 2017 & Jadot, I. et al (9) & Artigo de Revisão & $\begin{array}{l}\text { A exposição ao AA tem sido frequentemente associada } \\
\text { a neoplasias uroteliais. O mesmo foi classificado como } \\
\text { cancerígeno humano classe I pela IARC. }\end{array}$ \\
\hline 2018 & Kharchoufa L. et al (23) & Artigo de Revisão & $\begin{array}{l}\text { A ingestão regular de plantas contendo AA está associada à } \\
\text { progressão da fibrose intersticial renal, em última instância a } \\
\text { AAN. }\end{array}$ \\
\hline 2018 & V. Bunel et al (1) & Artigo de Revisão & $\begin{array}{l}\text { A ingestão oral de AA relaciona-se com o aparecimento de } \\
\text { UTUC, pelas suas capacidades mutagénicas e genetoxicas. }\end{array}$ \\
\hline 2018 & Zhang, H.-M. et al (5) & Artigo de Revisão & $\begin{array}{l}\text { Transversões A: T para T: A encontradas em TP53 } \\
\text { correspondem à conhecida especificidade mutagénica de AA } \\
\text { em células uroteliais, provocando carcinogenecidade. }\end{array}$ \\
\hline 2018 & Weiwei Li et al (10) & Artigo de Revisão & $\begin{array}{l}\text { Evidências significativas sugerem que o consumo de AA é uma } \\
\text { das principais causas de insuficiência renal terminal e cancro } \\
\text { do trato urinário superior. }\end{array}$ \\
\hline 2019 & Jelaković B. et al (4) & Artigo de Revisão & $\begin{array}{l}\text { AA demonstrou ser responsável pelo desenvolvimento de } \\
\text { UTUC associado ao BEN. }\end{array}$ \\
\hline 2019 & Han, J. et al (2) & Artigo de Revisão & $\begin{array}{l}\text { O AA é identificado como toxina que pode causar insuficiência } \\
\text { renal terminal associada ao carcinoma urotelial. }\end{array}$ \\
\hline 2020 & Ipek Suntar, Omer Faruk Yakıncı (17) & Artigo de Revisão & $\begin{array}{l}\text { Muitas pesquisas clínicas e in vivo mostraram a alta incidência } \\
\text { de cancro, nomeadamente renal e urotelial devido à exposição } \\
\text { a AA. }\end{array}$ \\
\hline
\end{tabular}




\section{Exposição ao Ácido Aristolóquico e Cancro}

Como mencionado anteriormente, o AA foi classificado como carcinogénico do grupo I pela IARC $(2,7,9,10,14)$. Desta forma, a sua ingestão está relacionada com o desenvolvimento de carcinoma urotelial do trato urinário superior (UTUC) $(2,4,9,11,25,26)$, um subconjunto raro de malignidades uroteliais que ocorrem na pelve renal e no ureter superior (2). Verificou-se que as taxas de mutação somática são surpreendentemente altas, excedendo outros tipos de cancro, como o cancro de pulmão associado ao tabagismo (20). Atualmente nenhuma terapia demonstrou capacidade de diminuir a incidência deste cancro que afeta aproximadamente $50 \%$ dos pacientes com AAN, sendo estes aconselhados a recorrer à nefroureterectomia bilateral preventiva $(6,11)$.

Apesar da relação evidente entre a ingestão de AA e UTUC, estudos investigam a possibilidade da ocorrência de carcinogénese noutros órgãos e tecidos como células renais $(2,4,19)$, fígado (3) e bexiga $(2,5,9)$. Relativamente à ocorrência de carcinogénese nestes tecidos, já foi concluído que o consumo de AA está amplamente relacionado com a hepatocarcinogenecidade em Taiwan, na China e por toda a Ásia $(3,19$, 27) e observou-se também alto risco de carcinogenicidade nos tecidos da bexiga associada à AAN e UTUC (5).

\section{Relação Dose-Resposta}

Ainda não existe consenso de qual ou se existe dose máxima segura relativamente ao consumo do ácido aristolóquico, diferindo com a subespécie da planta e a parte da mesma que é utilizada, bem como com as características dos indivíduos. Uma dose alta única ou a administração contínua de uma dose baixa de AA pode levar a uma reação tóxica (5). No caso do grupo de cerca de 100 mulheres belgas, a dose estimada consumida de AA foi de $25 \mathrm{mg} / \mathrm{kg}$ em média durante treze meses, por outro lado na China os doentes diagnosticados com AAN revelaram uma exposição intermitente de 1 a 10 anos com valores estimados entre 0,7 e 1,5 mg/dia (26). Num outro estudo as ingestões diárias estimadas (EDls) de AA foram 1,7 x 10-3 a $30 \mu \mathrm{g} / \mathrm{kg} / \mathrm{dia}$ (14).

\section{ANÁLISE CRÍTICA}

Apesar de usualmente utilizadas para fins terapêuticos já foi comprovado que as plantas da família Aristolochia têm um efeito tóxico devido à sua alta composição em ácido aristolóquico. Os valores das doses de AA que provocam toxicidade encontrados nesta pesquisa foram controversos e inconclusivos, existindo ainda alguns pesquisadores que acreditam que o AA pode induzir mutações genéticas irreversíveis, portanto essa genotoxicidade não tem uma "dose segura" (5).

Devido a vários avisos sobre os efeitos tóxicos dos AAs pela Food and Drug Administration (FDA) dos Estados Unidos da América (EUA), pela European Medicines Agency (EMA) (9) e pelas autoridades reguladoras de outros países, a venda e o uso de produtos que contêm AA foram proibidos ou restritos na sua maioria (2), como aconteceu na Austrália, Canadá, Nova Zelândia e em muitos países asiáticos (por exemplo, Japão) (14). Além destas entidades, também a European Food Safety Authority (EFSA) emitiu um Compêndio de produtos botânicos relatados como contendo substâncias de possível preocupação para a saúde humana quando usadas em alimentos e suplementos alimentares, no qual se inseria o ácido aristolóquico (28). Desde 2004, a União Europeia (EU) não aprovou quaisquer medicamentos à base de plantas com AA, banindo-os e proibindo a sua vendo na maioria dos países $(2,11)$. Contudo os suplementos alimentares que contêm plantas que não constem na lista de plantas permitidas pela EU e respetivas partes colocados no mercado, puderam ser comercializados até ao seu esgotamento (29).
No entanto nos países endémicos como é frequente a contaminação por AA através do solo ou das próprias sementes destas plantas, desenvolveram-se técnicas para a possível redução deste ácido nos alimentos como a adição de magnésio, ácido ascórbico, cisteína, ácido cítrico ou glutationa durante o cozimento. No caso da água deve-se ferver num recipiente de aço inoxidável $(\mathrm{Fe})$ com algumas frutas cítricas, como o limão (ácidos cítrico e ascórbico) (10).

Dois dos métodos de cocção mais utilizados na região dos Balcãs para a redução da concentração de AA na massa de farinha são cozer e ferver em água, com a obtenção de percentagens de redução dos níveis de AAl e AAll em aproximadamente $30 \%$ e $20 \%$, respetivamente (10), sendo o AAl o composto principal, mais tóxico e carcinogénico $(5,6,13)$.

\section{CONCLUSÕES}

Verificou-se o cumprimento do objetivo desta revisão da literatura, observando-se uma relação direta entre os efeitos tóxicos derivados do consumo de AA como nefrotoxicidade, genotoxicidade e carcinogenicidade. Estes efeitos refletem-se principalmente na ocorrência de AAN e UTUC, mas também no desenvolvimento de cancros noutros tecidos $(6,10,18)$.

Ainda que tenha sido proibido a venda e o uso de produtos à base de plantas da família Aristolochia, estão disponíveis na internet em mais de 100 sites sem avaliação de segurança toxicológica pré-comercialização, podendo ser adquiridos com bastante facilidade. Em Portugal, os produtos desta planta encontram-se também disponibilizados online, como são exemplo produtos que contenham "Cipó-mil-homens" (Aristolochia cymbiphera), sob a forma de sementes e preparados para infusão, apesar da advertência por parte da INFARMED, relativamente às reações adversas provocadas por esta espécie (30).

O seu uso ainda permitido sob a supervisão de praticantes de medicina chinesa, uma vez que populações asiáticas acreditam que os fitoterápicos tradicionais são mais naturais e seguros que os medicamentos ocidentais.

Os efeitos nefrotóxicos do AA são irreversíveis e os seus efeitos carcinogénicos podem demorar até trinta anos a manifestar-se após a exposição inicial do indivíduo, podendo tornar-se num grande problema de saúde pública nos próximos anos.

Por fim para controlar a toxicidade do AA, a presença e as doses mínimas tóxicas de AA em materiais e preparações medicinais deve ser mais estudada, assim como os métodos para desintoxicação eficaz, descontaminação de alimentos e/ou medicamentos que possam reduzir toxicidade do AA.

\section{REFERÉNCIAS BIBLIOGRÁFICAS}

1. Bunel V, Souard F, Antoine MH, Stévigny C, Nortier JL. Nephrotoxicity of Natural Products: Aristolochic Acid and Fungal Toxins. Compr Toxicol Third Ed. 2018;14-15(September 2016):340-79.

2. Han J, Xian Z, Zhang Y, Liu J, Liang A. Systematic overview of aristolochic acids: Nephrotoxicity, carcinogenicity, and underlying mechanisms. Front Pharmacol. 2019;10(JUN)

3. Ji X, Feng G, Chen G, Shi T. Lack of correlation between aristolochic acid exposure and hepatocellular carcinoma. Sci China Life Sci. 2018;61(6):727-8.

4. Jelaković B, Dika Ž, Arlt VM, Stiborova M, Pavlović NM, Nikolić J, et al. Balkan Endemic Nephropathy and the Causative Role of Aristolochic Acid. Semin Nephrol. 2019;39(3):284-96.

5. Zhang HM, Zhao XH, Sun ZH, Li GC, Liu GC, Sun LR, et al. Recognition of the toxicity of aristolochic acid. J Clin Pharm Ther. 2019;44(2):157-62.

6. Ma L, Qin Y, Shen Z, Bi H, Hu H, Huang M, et al. Aristolochic acid I is a substrate of BCRP but not P-glycoprotein or MRP2. J Ethnopharmacol [Internet]. 2015;172:430-5. Available from: http://dx.doi.org/10.1016/j.jep.2015.07.011. 
7. Chan CK, Tung KK, Pavlović NM, Chan W. Remediation of aristolochic acidcontaminated soil by an effective advanced oxidation process. Sci Total Environ. $2020 ; 720$.

8. Wang X, Shi GR, Liu YF, Li L, Chen RY, Yu DQ. Aristolochic acid derivatives from the rhizome of Arisolochia championii. Fitoterapia. 2017;118:63-8.

9. Jadot I, Declèves AE, Nortier J, Caron N. An integrated view of aristolochic acid nephropathy: Update of the literature. Int J Mol Sci. 2017;18(2).

10. Li W, Chan CK, Wong YL, Chan KKJ, Chan HW, Chan W. Cooking methods employing natural anti-oxidant food additives effectively reduced concentration of nephrotoxic and carcinogenic aristolochic acids in contaminated food grains [Internet]. Vol. 264, Food Chemistry. 2018. 270-276 p. Available from: https://doi.org/10.1016/j. foodchem.2018.05.052.

11. Luciano RL, Perazella MA. Aristolochic Acid Nephropathy: Epidemiology, Clinical Presentation, and Treatment. Drug Saf. 2015;38(1):55-64.

12. Stiborová M, Frei E, Arlt VM, Schmeiser HH. Metabolic activation of carcinogenic aristolochic acid, a risk factor for Balkan endemic nephropathy. Mutat Res - Rev Mutat Res. 2008;658(1-2):55-67.

13. Ye J, Qian Z, Xue M, Liu Y, Zhu S, Li Y, et al. Aristolochic acid I aggravates renal injury by activating the C3a/C3aR complement system. Toxicol Lett. 2019;312(December 2018):118-24

14. Abdullah R, Diaz LN, Wesseling S, Rietjens IMCM. Risk assessment of plant food supplements and other herbal products containing aristolochic acids using the margin of exposure (MOE) approach. Food Addit Contam - Part A Chem Anal Control Expo Risk Assess [Internet]. 2017;34(2):135-44. Available from: http://dx.doi.org/10.1080 /19440049.2016.1266098.

15. Bastek H, Zubel T, Stemmer K, Mangerich A, Beneke S, Dietrich DR. Comparison of Aristolochic acid I derived DNA adduct levels in human renal toxicity models. Toxicology. 2019;420(January):29-38.

16. Stiborová M, Frei E, Schmeiser HH. Biotransformation enzymes in development of renal injury and urothelial cancer caused by aristolochic acid. Kidney Int. 2008;73(11):1209-11.

17. Süntar I, Yakıncı ÖF. Potential risks of phytonutrients associated with high-dose or long-term use. Phytonutrients Food From Tradit to Ration Usage. 2019;137-55.

18. Rosenquist TA, Grollman AP. Mutational signature of aristolochic acid: Clue to the recognition of a global disease. DNA Repair (Amst) [Internet]. 2016;44:205-11. Available from: http://dx.doi.org/10.1016/j.dnarep.2016.05.027.

19. Wang J bo, Bai Z fang, Xiao X he. Letter to the Editor: Is Aristolochic Acid the Major Cause of Liver Cancer in China and Asia? Hepatology. 2020;71(3):1130.

20. Michl J, Ingrouille MJ, Simmonds MSJ, Heinrich M. Naturally occurring aristolochic acid analogues and their toxicities. Nat Prod Rep. 2014;31(5):676-93.

21. Debelle FD, Vanherweghem JL, Nortier JL. Aristolochic acid nephropathy: A worldwide problem. Kidney Int. 2008;74(2):158-69.

22. Ekar T, Kreft S. Common risks of adulterated and mislabeled herbal preparations. Food Chem Toxicol [Internet]. 2019;123:288-97. Available from: https://doi. org/10.1016/j.fct.2018.10.043.

23. Kharchoufa L, Merrouni IA, Yamani A, Elachouri M. Profile on medicinal plants used by the people of North Eastern Morocco: Toxicity concerns. Toxicon [Internet]. 2018;154:90-113. Available from: https://doi.org/10.1016/j.toxicon.2018.09.003.

24. Malik A, Bissinger R, Calabrò S, Faggio C, Jilani K, Lang F. Aristolochic acid induced suicidal erythrocyte death. Kidney Blood Press Res. 2014;39(5):408-19.

25. Cheng WC, Ng CS, Poon NL. Herbal Medicines and Phytopharmaceuticals Contaminations. Encycl Forensic Sci Second Ed. 2013;280-8.

26. Riffault-Valois L, Wattez C, Langrand J, Boucaud-Maitre D, Gaslonde T, Colas C, et al. Health risk associated with the oral consumption of "Chiniy-tref", a traditional medicinal preparation used in Martinique (French West Indies): Qualitative and quantitative analyses of aristolochic acids contained therein. Toxicon [Internet]. 2019;172:53-60. Available from: https://doi.org/10.1016/j.toxicon.2019.10.241.

27. Ng AWT, Poon SL, Huang MN, Lim JQ, Boot A, Yu W, et al. Aristolochic acids and their derivatives are widely implicated in liver cancers in Taiwan and throughout Asia. Sci Transl Med. 2017;9(412).
28. Food E, Authority S. Compendium of botanicals reported to contain naturally occuring substances of possible concern for human health when used in food and. 2012;10(5).

29. notification_draft_2017_276_I_PT-Ministerio-da-Saude-UE.

30. INFARMED. O que acontece às notificações de RAM quando chegam ao INFARMED? Bol Farm [Internet]. 2006; Available from: https://www.infarmed. pt/portal/page/portal/INFARMED/PUBLICACOES/TEMATICOS/BOLETIM_ FARMACOVIGILANCIA/farmac_4tr_1 port.pdf.

31. Vanherweghem J. and Mushroom Nephrotoxicity. 1993. 